\title{
Prevalence of overweight and obesity in grade 1 learners in the North West Province of South Africa: The NW-CHILD Study
}

\author{
A E Pienaar, PhD; G Kruger, MSc \\ Physical Activity, Sport and Recreation (PhaSRec), Faculty of Health Science, North-West University, Potchefstroom, South Africa
}

Corresponding author: A E Pienaar (anita.pienaar@nwu.ac.za)

\begin{abstract}
Objectives. To determine the prevalence of overweight and obesity among grade 1 learners, taking into account age, gender, race and school socioeconomic profile.

Methods. The study is based on the baseline prevalence of overweight and obesity as part of the ongoing 6-year longitudinal NW Child Health Integrated Learning and Development (NW-CHILD) study. Stratified random sampling was used to identify 20 schools from four educational districts across all five quintiles of schools in the North West Province (NWP) of South Africa (SA). A total of 816 (419 boys, 397 girls) grade 1 learners with a mean age of 6.80 (standard deviation 0.39) years participated in the study, including 567 black learners, 218 white learners and 31 learners from other race groups. Standard anthropometric techniques and international body mass index (BMI) cut-off points for children were used to determine overweight and obesity.

Results. A combined prevalence of overweight and obesity $(\mathrm{Ow} / \mathrm{Ob})$ of $11.1 \%$ was found, of which $7.5 \%$ were overweight and $3.6 \%$ obese. Although 7-year-old children showed a significantly higher prevalence of overweight (10.5\%) than 6-year-old children $(6.3 \%$; $p<0.05)$, obesity levels were more prevalent among 6-year-old children (4.7\%) than 7-year-old children (2.3\%). Although not significant, a higher prevalence of overweight $(9.3$ v. $6.4 \%)$ and obesity ( $4.3 \%$ v. $3.3 \%)$ was found in girls than boys. For the whole sample, white children displayed a significantly higher prevalence of $\mathrm{Ow} / \mathrm{Ob}$ compared with black children $(19.7 \% \mathrm{v} .8 .8 \% ; p<0.05)$, and the prevalence of $\mathrm{Ow} / \mathrm{Ob}$ was higher in 4 th- (18.1\%) and 5th- (21.2\%) quintile schools (which are associated with higher socioeconomic status (SES)) than in quintile 1 to quintile 3 schools $(5.1 \%, 8.7 \%, 6.1 \%$, respectively; $p<0.05)$.

Conclusions. More than $10 \%$ of grade 1 learners in the NWP of SA were overweight or obese, with the prevalence being significantly lower in lower SES schools and among black children. Prevention strategies are needed to combat overweight and obesity, and the associated negative consequences of these health risks. Obesity levels in black children should also be monitored because of continuing economic transition, and taking into account increasing overweight and obesity in black South African adults.
\end{abstract}

S Afr J SM 2014;26(4):109-114. DOI:10.7196/SAJSM.519

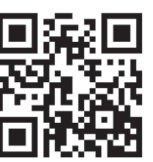

Overweight and obesity have become a global epidemic, especially among children. ${ }^{[1]}$ The statement from Hills et al. ${ }^{[1]}$ emphasises the seriousness of obesity in children: 'Today's generation of children will be the first for over a century for whom life expectancy falls.' Overweight and obesity can be defined as abnormal excessive accumulation of body fat, ${ }^{[2]}$ which is the result of an imbalance between energy intake and energy expenditure. One billion people in both developed and developing countries are affected by overweight and obesity. ${ }^{[2]}$ In 2010, nearly 43 million children $<5$ years old worldwide were overweight. ${ }^{[2]}$ The prevalence of overweight and obesity in Canada, Norway and America in children aged between 6 and 11 years was $6.3 \%, 10.1 \%$ and 20.7\%, respectively. ${ }^{[3]}$ While the prevalence of overweight in children has doubled over the past 2 decades, severe obesity is also becoming a more general phenomenon among children; a study in America indicates that rates of severe obesity have tripled in the last 25 years, where $3.8 \%$ of children aged $2-19$ years were found to be severely obese in the period 1999 - 2004, with significant differences in race, gender and poverty. ${ }^{[4]}$

Some parts of South Africa (SA) are more affected by overweight and obesity, and possible contributing factors are improved socioeconomic status (SES), urbanisation and a decrease in physical activity ${ }^{[5]}$ A study of 6 - 13-year-old SA children of different races found that $14.0 \%$ of boys and $17.9 \%$ of girls were overweight, and $3.2 \%$ of boys and $4.9 \%$ of girls were obese, with white children more overweight and obese than black and mixed-ancestry children of 6 or 7 years. ${ }^{[6]}$ The National Food Consumption Survey (NFCS) ( $N=2$ 894), which investigated 1 - 8-year-old children in 1999, indicated that $6.7 \%$ of children were overweight and $3.7 \%$ were obese. ${ }^{[7]}$ SA statistics released in 2013 for 10 - 14-year-olds indicated that overweight and obesity were higher in girls $(16.7 \%$ and $5.6 \%$, respectively) than in boys $\left(7.5 \%\right.$ and $2.7 \%$, respectively) ${ }^{[8]}$ For 6 - 9-year-old children, an overweight prevalence of $8.4 \%$ in 2013 v. $7.8 \%$ in the 2005 NFCS, and an obesity prevalence of $3.4 \%$ in 2013 v. $2.5 \%$ in the 2005 NFCS, are reported. ${ }^{[8]}$ No studies report data on severely obese SA children.

Obesity places high demands on the health of children. Some obesity-related conditions have immediate health effects, while others have long-term chronic consequences. ${ }^{[9]}$ Overweight and obesity can lead to numerous negative health conditions, including asthma, cardiovascular illnesses, type 2 diabetes, hypertension and obstructive sleep apnoea. ${ }^{[9]} \mathrm{A}$ more sedentary lifestyle is also preferred by obese children compared with non-obese children, and obese children 
are less active. Lowered physical activity levels lead to lower energy expenditure and increased risk of obesity and poor health later in life. Graft et al. ${ }^{[10]}$ reported lower gross motor development and aerobic capacity in obese compared with non-obese grade 1 learners with a mean age of 6.7 years in Germany. A study by D'Hondt et al. ${ }^{[11]}$ found that the general level of motor coordination in obese children is lower when compared with normal-weight children, while inadequate locomotor skills (i.e. jumping and kicking) were also reported. ${ }^{[10,12]}$ Children's fine motor skills are also negatively influenced by overweight and obesity. Although overweight and obesity have been studied among SA children, none of these studies have focused on the school beginner. A knowledge gap exists in our understanding of the rates of overweight and obesity in school beginners in SA, and how increased body mass relates to age, gender, race and SES. Because overweight and obesity hamper development and wellbeing of school beginners, it is important to obtain more information regarding the current prevalence of these conditions. The objective of this study was to fill this knowledge gap by identifying the prevalence of overweight and obesity among grade 1 learners in the North West Province (NWP) of SA, and explore the relationship of overweight and obesity to age, gender, race and school type.

\section{Method}

\section{Sample size and sampling procedure}

The research was part of the NW-CHILD (North West Child Health Integrated Learning and Development) longitudinal study (2010 2016). The sample formed part of the baseline population of the NWCHILD study (2010) and subjects were selected by means of a stratified random sample. Stratification was done by school district, gender and school type in collaboration with the Statistical Consultation Service of North-West University (NWU). To determine the sample, a list of schools in the NWP was obtained from the Department of Basic Education. From these schools, which are grouped into eight education districts, each representing 12 - 22 regions with $\sim 20$ schools (minimum 12 , maximum 47) per region, stratified random sampling was used to select regions and schools with regard to population density and school status (quintile 1, i.e. schools from very low economic sectors to quintile 5, i.e. schools from very high economic sectors). The total sample comprised 816 learners (419 boys and 397 girls) with a mean age of 6.78 (standard deviation 0.39 ) years. The distribution of the learners in the different school quintiles was as follows: quintile 1, $n=138$; quintile 2, $n=159$; quintile $3, n=173$; quintile $4, n=145$; and quintile $5, n=175$. The ethnic distribution was 567 black, 218 white, 20 mixed-ancestry and 11 Indian learners.

\section{Ethical clearance}

Ethical approval for the study was obtained from the ethics committee of the NWU (No. 0007009 A1). Permission was also obtained from the Department of Basic Education of the NWP and the principals from the selected schools. Informed consent had to be provided for each learner by their parents before they were allowed to participate in the study.

\section{Anthropometry}

Anthropometric measurements included: height $(\mathrm{cm})$, body mass $(\mathrm{kg}$ ), skinfolds (subscapular and triceps, $\mathrm{mm}$ ) and waist circumference $(\mathrm{cm})$. These variables were measured by trained postgraduate students in Human Movement Sciences, specialising in Kinderkinetics, who were all level 2 kinanthropometrists. All measurements were done in accordance with the protocol of the International Society for the Advancement of Kinanthropometry. ${ }^{[13]}$ One researcher measured a specific anthropometric measurement throughout the study for reliability purposes. Height was measured barefoot to the nearest $0.1 \mathrm{~cm}$ by means of a portable stadiometer, and body mass was measured with an electronic scale (BF 511, Omron, Healthcare Europe) to the nearest $0.1 \mathrm{~kg}$. From the height and body mass measurements, the body mass index (BMI) was calculated for each participant (body mass $(\mathrm{kg}) /$ height $\left(\mathrm{m}^{2}\right)$ ). The triceps and subscapular skinfolds were measured with a pair of skinfold callipers (Harpenden, UK) and each skinfold was measured twice to obtain the average of the two measurements. These skinfold measurements were selected because they show the highest association with the overall percentage of fat in children. Intrarater reliability was determined by intraclass correlation coefficients, which showed good reliability for the subscapular $(r=0.994)$ and the triceps $(r=0.995)$ skinfolds.

The prevalence of overweight and obesity was determined by using the international age-specific cut-off points provided by Cole et al.$^{[14]}$ Children are at risk of overweight and obesity if their BMI is $>85$ th and 95th percentiles for age and gender, respectively. ${ }^{[14]}$

\section{Data analysis}

Statistica ${ }^{[15]}$ (Statsoft, USA) was used to analyse the data. Data were analysed as percentages, ranges (minimum, maximum), means and standard deviations. Differences in BMI between genders, age groups and black and white learners were determined by means of independent $t$-testing, where $p<0.05$ was considered a significant difference. Two-way frequency tables were also used for further analyses of the data, where the group was divided according to age, gender, race and school type. Statistical significance of differences $(p<0.05)$ was determined by Pearson $\chi^{2}$ analysis, while Cramér's V was used to determine effect sizes; the following values were used as an estimation of practical significance: 0.1 (small); 0.3 (moderate); 0.5 (large). ${ }^{[16]}$

\section{Results}

Table 1 displays the mean height, weight, fat percentage, skinfold and BMI for the total group and the group separated into 6- and 7-yearolds, for the different racial groups, while Table 2 presents BMI values for boys and girls divided into 6- and 7-year-old groups. Owing to the small sample size of Indian and mixed-ancestry learners, these racial groups were excluded from comparative analysis. White learners had significantly higher mean height, weight, triceps skinfold and fat percentage compared with black learners for the whole group and at 6 and 7 years of age. Only the subscapular skinfold did not differ significantly between the black and white learners for the group as a whole and for 7-year-olds.

Table 2 indicates no significant gender differences $(p<0.05)$ in BMI for the whole group or 6- and 7-year-old subgroups. The BMI of white boys (6- and 7-year-olds) and white girls (7-year-old group only) was significantly higher than their black counterparts of the same age and sex. Similarly, when the 6- and 7-year-old 


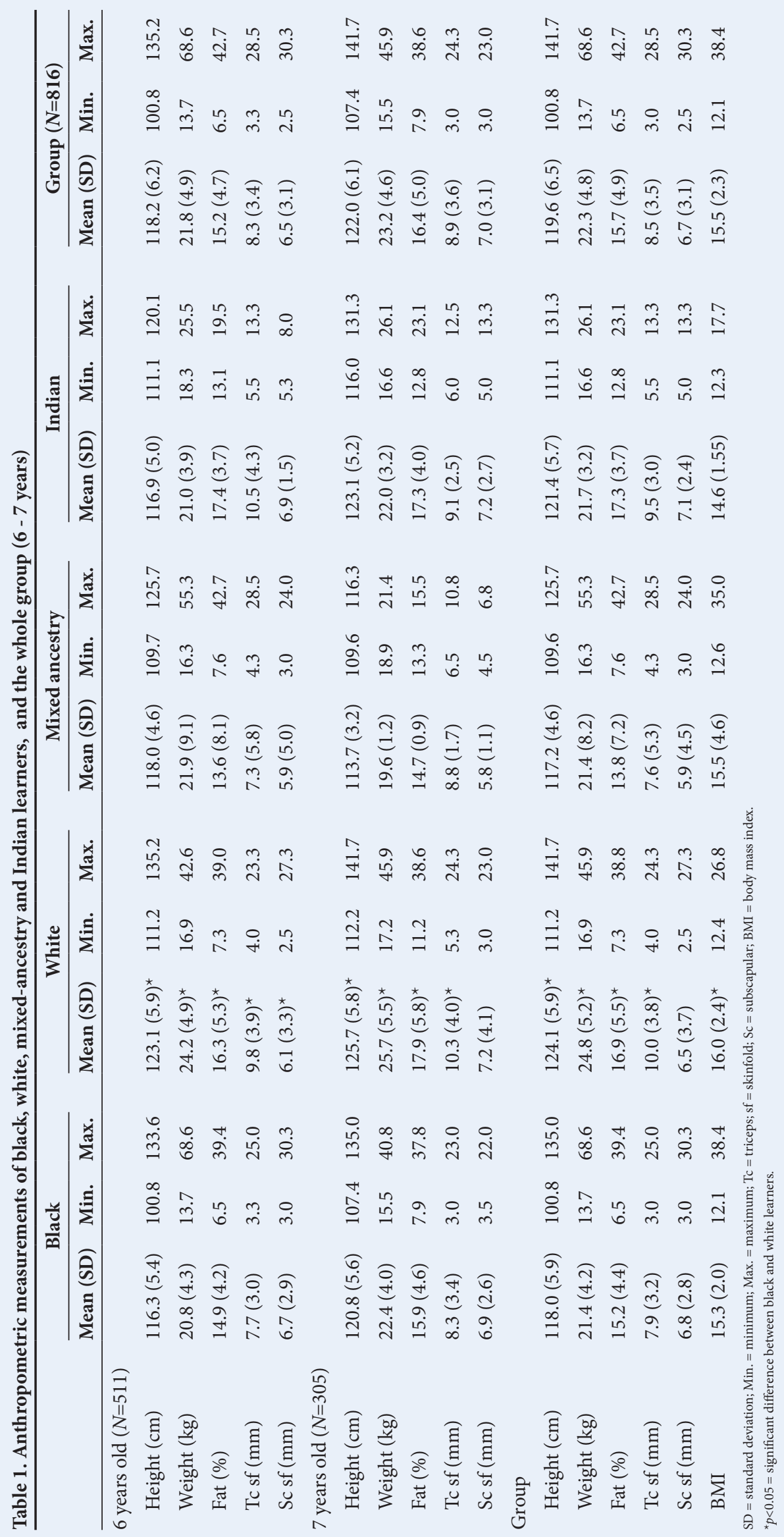

boys and girls groups were combined, the white learners had a significantly greater BMI than the black learners.

Table 3 shows that for the whole group of grade 1 learners, $7.5 \%$ were overweight and $3.6 \%$ were obese, a total prevalence of overweight and obesity of $11.1 \%$. For the whole group, overweight was most prevalent in girls (9.3\%), white learners (13.3\%) and quintile 5 schools (16.2\%). Obesity had the highest prevalence in girls (4.3\%), white learners (6.4\%) and quintile 4 schools (7.1\%). A significantly higher prevalence of overweight in 7-year-old compared with 6 -year-old (10.5 v. 6.3\%, respectively) learners was found (Table 3); however, obesity levels were significantly lower in the 7-year-old group compared with the 6-year-old group (2.3 v. $4.7 \%$, respectively), although these differences only showed small practical significance (Cramér's V=0.1).

BMI and the prevalence of overweight and obesity were not significantly different between boys and girls (Tables 2 and 3).

For the whole group, ages 6 and 7 years, white learners had a higher prevalence of obesity and overweight compared with black learners (Table 3). The overall prevalence of overweight was also significantly higher $(p<0.01$; Cramér's V $=0.2$ ) in quintile 4 and 5 schools (11.0\% and $16.2 \%$, respectively) compared with quintile 1 (5.2\%), $2(4.4 \%)$ and $-3(2.3 \%)$ schools. Similar trends of higher percentages of obesity levels were also seen in quintile 4 and 5 schools. In the 7-year-old group, obesity was only seen among learners in the quintile 4 and 5 schools, with no evidence of obesity in quintile 1 - 3 schools. In the overall group, obesity levels of school beginners in quintile 4 schools (7.1\%) was significantly higher than in the other quintile schools $(p<0.05$; Cramér's V=0.2).

\section{Discussion}

The objective of this study was to determine the prevalence of overweight and obesity in grade 1 learners in the NWP of SA and to determine whether overweight and obesity are related to age, gender, race 
Table 2. Body mass index $\left(\mathrm{kg} / \mathrm{m}^{2}\right)$ of black, white, mixed ancestry, and Indian boys and girls overall

\begin{tabular}{|c|c|c|c|c|c|c|c|c|c|c|}
\hline \multirow[b]{2}{*}{ Age } & \multicolumn{2}{|l|}{ All } & \multicolumn{2}{|l|}{ Black } & \multicolumn{2}{|c|}{ White } & \multicolumn{2}{|c|}{ Mixed ancestry } & \multicolumn{2}{|c|}{ Indian } \\
\hline & Mean (SD) & $n$ & Mean (SD) & $n$ & Mean (SD) & $n$ & Mean (SD) & $n$ & Mean (SD) & $n$ \\
\hline \multicolumn{11}{|l|}{ Boys } \\
\hline 6 years & $15.6(2.3)$ & 250 & $15.3(1.7)$ & 168 & $16.1(2.3)^{\star}$ & 71 & $16.3(6.7)$ & 10 & $13.5(0.0)$ & 1 \\
\hline 7 years & $15.5(2.2)$ & 169 & $15.2(1.8)$ & 110 & $16.2(2.7)^{\star}$ & 50 & $16.8(0.0)$ & 1 & $14.5(1.4)$ & 5 \\
\hline Group & $15.5(2.2)$ & 420 & $15.3(1.8)$ & 278 & $16.1(2.4)^{* \dagger}$ & 122 & $16.3(6.3)$ & 11 & $14.3(1.4)$ & 6 \\
\hline \multicolumn{11}{|l|}{ Girls } \\
\hline 6 years & $15.4(2.5)$ & 261 & $15.32 .5)$ & 186 & $15.72 .4)$ & 64 & $14.3(1.4)$ & 6 & $16.3(2.1)$ & 2 \\
\hline 7 years & $15.6(1.9)$ & 136 & $15.4(1.7)$ & 104 & $16.4(2.5)^{\star}$ & 29 & $14.6(1.0)$ & 3 & $14.3(1.5)$ & 3 \\
\hline Group & $15.5(2.3)$ & 396 & $15.4(2.3)$ & 290 & $15.9(2.5)^{* \dagger}$ & 93 & $14.4(1.2)$ & 9 & $15.1(1.8)$ & 5 \\
\hline
\end{tabular}

and SES. A prevalence of $11.1 \%$ of overweight (7.6\%) and obesity $(3.5 \%)$ was found in the total group of grade 1 learners. A significant age effect was found, indicating a significant rise in the prevalence of overweight from $6.3 \%$ in 6-year-old learners to $10.5 \%$ in 7 -year-olds. Obesity rates $(3.6 \%)$ were lower than overweight rates in the total group, where $4.8 \%$ of 6 -year-old learners and $2.3 \%$ of 7 -year-old learners were obese. It could perhaps be speculated that the above results point towards a weight loss between the ages of 6 and 7 years, where some children changed from obese to overweight. As this is the first phase of a longitudinal study, subsequent assessments will show whether this is indeed an age-related trend. Although the overweight statistics of 7-year-old learners were higher than in 6-year-olds, none of the 7-year-old's in quintile 1 - 3 schools were obese. Girls, white children and children of higher SES also had higher levels of overweight and obesity compared with the other groups. A recent review on overweight and obesity in children and adolescents in SA also confirmed that the prevalence of overweight and obesity among children and adolescents in SA is strongly dependent on age, gender and ethnicity. ${ }^{[17]}$

The overall prevalence rates of overweight and obesity found in this study are lower when compared with studies conducted worldwide on similar age groups, but similar to most studies done in SA among learners of the same age. ${ }^{[6,7,18,19]}$ This may be owing to different thresholds to define overweight and obesity being used in some of these studies compared with the cut-off values used in our study, ${ }^{[14]}$ making direct comparisons difficult. Studies done in Canada, Norway and America on children aged 6 - 11 years report the prevalence of overweight and obesity to be $6.3 \%, 10.1 \%$ and $20.7 \%$, respectively. ${ }^{[3]}$ The thresholds from the Centers for Disease Control and Prevention (CDC) were used in these studies, where the CDC growth charts are based on information for US children. ${ }^{[3]} \mathrm{A}$ study on French children aged 7 - 9 years $(N=1582)$, which was also based on the thresholds on the CDC growth charts, reported that $20.6 \%$ of the children were overweight and $6.4 \%$ obese. ${ }^{[18]}$ Padez et al. ${ }^{[19]}$ undertook a study of 7 - 9-year-old Portuguese children, which indicated that $31.5 \%$ were overweight or obese $(20.3 \%$ overweight, $11.3 \%$ obese). These researchers used the cut-off points of the International Obesity Task Force (IOTF) to define overweight and obesity. ${ }^{[19]}$ A study done by Skelton et al. ${ }^{[4]}$ in America found that
$3.8 \%$ of the 2 - 19-year-old children who participated in the study already showed severe obesity.

The majority of SA studies ${ }^{[6,7,20-22]}$ have reported a similar prevalence for overweight and obesity among children of the same age group. The results of the National Food Consumption Survey based on the IOTF cut-off points, conducted on children between the ages of 1 and 8 years ( $N=2894)$, showed that $6.7 \%$ of children could be classified as overweight and $3.7 \%$ as obese. ${ }^{[7]}$ Kruger et al. ${ }^{[22]}$ assessed anthropometric status in SA women and children in 2005 in order to document temporal trends in selected anthropometric parameters. When the BMI cut-off points for international use ${ }^{[14]}$ were used to define overweight and obesity in 1 - 9-year-old children, $10 \%$ nationally were overweight and $4 \%$ obese. A study on 579 primary school children between the ages of 8 and 10 years in a rural magisterial district of KwaZulu-Natal found that 3.1\% of the children were obese. ${ }^{[20]}$ In another study undertaken by Jinabhai et al. ${ }^{[21]}$ in KwaZulu-Natal on 802 children between the ages of 8 and 11 years, the incidence of overweight varied between 0.4 and $13.3 \%$, and obesity between 0.1 and 3.7\%. Two sets of criteria were used by Jinabhai et $a l{ }^{[21]}$ to measure overweight and obesity, namely the WHO standard based on the 85 th and 95 th percentiles, and the IOTF criteria.

In the current study, the results further indicated a higher, although non-significant, prevalence of overweight and obesity among girls than boys in the overall group, and between the 6- and 7-year-old girls compared with 6- and 7-year old boys. Another SA study ${ }^{[6]}$ found that girls at the ages of 6 and 7 years ( 6 years $11.9 \%$; 7 years $11.8 \%$ ) had a higher prevalence of overweight when compared with boys (6 years $8.0 \%$; 7 years 9.2\%). Armstrong et al., ${ }^{[6]}$ who also used the cut-off points of Cole et al., ${ }^{[14]}$ reported similar results among 7-year-old girls and boys, where the girls $(5.8 \%)$ had a higher prevalence of obesity than the boys (2.5\%). The results of Armstrong et al., ${ }^{[6]}$ however, differed from the results of our study with regard to 6-year-old children, where the 6-year-old boys had a higher prevalence of obesity than the girls (6.0\% v. $4.1 \%$, respectively). However, other studies in SA also report a higher prevalence of overweight and obesity among girls than among boys. ${ }^{[20,21]}$

Significant differences were found in the overweight and obesity prevalence rates of white and black children, indicating that white learners are significantly more overweight and obese $(19.7 \%)$ than 
Table 3. Sample size and percentage of Grade 1 learners ( 6 and 7 years) by gender, race and school type, classified as overweight or obese ${ }^{\star}$

\begin{tabular}{|c|c|c|c|c|c|}
\hline & $\begin{array}{l}\text { Normal, } \\
n(\%)\end{array}$ & $\begin{array}{l}\text { Overweight, } \\
n(\%)\end{array}$ & $\begin{array}{l}\text { Obese, } \\
n(\%)\end{array}$ & $\begin{array}{l}\text { Combined } \\
\text { Ow/Ob, } n(\%)\end{array}$ & $\begin{array}{l}\text { Total, } \\
N\end{array}$ \\
\hline \multicolumn{6}{|l|}{6 years } \\
\hline Boys & $220(91.6)$ & $11(4.4)$ & $10(4.0)$ & $21(8.4)$ & 250 \\
\hline Girls & $226(86.6)$ & $21(8.1)$ & $14(5.4)$ & $35(13.5)$ & 261 \\
\hline White & $113(81.9)$ & $16(11.6)^{\dagger}$ & $9(6.5)^{\dagger}$ & $25(18.1)$ & 138 \\
\hline Black & $325(91.8)$ & $15(4.2)^{\dagger}$ & $14(4.0)^{\dagger}$ & $29(8.2)$ & 354 \\
\hline Quintile 1 & 87 (90.8) & $5(5.2)$ & $4(4.2)$ & $9(9.4)$ & 96 \\
\hline Quintile 2 & $106(93.8)$ & $3(2.7)$ & $4(3.6)$ & $7(6.3)$ & 113 \\
\hline Quintile 3 & $122(96.8)$ & $1(0.8)$ & $3(2.4)$ & $4(3.2)$ & 126 \\
\hline Quintile 4 & $71(78.0)$ & $12(13.2)$ & $8(8.8)$ & $20(22.0)$ & 91 \\
\hline Quintile 5 & 69 (81.2) & $11(12.9)$ & $5(5.9)$ & $16(18.8)$ & 85 \\
\hline Group & $455(89.0)$ & $32(6.3)^{\dagger}$ & $24(4.7)$ & $56(12.0)$ & 511 \\
\hline \multicolumn{6}{|l|}{7 years } \\
\hline Boys & $149(88.2)$ & $16(9.5)$ & $4(2.4)$ & $20(11.9)$ & 169 \\
\hline Girls & $117(86.0)$ & $16(11.8)$ & $3(2.2)$ & $19(14.0)$ & 136 \\
\hline White & $62(77.5)$ & $13(16.3)$ & $5(6.3)$ & $18(22.6)$ & 80 \\
\hline Black & $192(90.1)$ & $19(8.9)^{\dagger}$ & $2(1.0)^{\dagger}$ & $21(9.9)$ & 213 \\
\hline Quintile 1 & $56(94.9)$ & $3(5.1)$ & 0 & $3(5.1)$ & 59 \\
\hline Quintile 2 & $42(91.3)$ & $4(8.7)$ & 0 & $4(8.7)$ & 46 \\
\hline Quintile 3 & $46(93.9)$ & $3(6.1)$ & 0 & $3(6.1)$ & 49 \\
\hline Quintile 4 & $55(87.3)$ & $5(7.9)$ & $3(4.8)$ & $8(12.7)$ & 63 \\
\hline Quintile 5 & $67(76.1)$ & $17(19.3)$ & $4(4.6)$ & $21(23.9)$ & 88 \\
\hline Group & $266(87.2)$ & $32(10.5)^{\dagger *}$ & $7(2.3)$ & $39(12.8)$ & 305 \\
\hline \multicolumn{6}{|l|}{ Group } \\
\hline Boys & $378(90.2)$ & $27(6.4)$ & $14(3.3)$ & $41(9.7)$ & 419 \\
\hline Girls & $343(86.4)$ & $37(9.3)$ & $17(4.3)$ & $54(13.6)$ & 397 \\
\hline White & $175(80.3)$ & $29(13.3)^{\dagger \neq}$ & $14(6.4)^{\dagger \neq}$ & $43(19.7)^{\dagger}$ & 218 \\
\hline Black & $517(91.2)$ & $34(6.0)$ & $16(2.8)$ & $50(8.8)^{\dagger}$ & 567 \\
\hline Quintile 1 & $143(92.3)$ & $8(5.2)$ & $4(2.6)$ & $12(7.8)$ & 155 \\
\hline Quintile 2 & $148(93.1)$ & $7(4.4)$ & $4(2.5)$ & $11(6.9)$ & 159 \\
\hline Quintile 3 & $168(96.0)$ & $4(2.3)$ & $3(1.7)$ & $7(4.0)$ & 175 \\
\hline Quintile 4 & $126(81.8)$ & $17(11.0)^{\dagger \ddagger}$ & $11(7.1)^{\dagger \ddagger}$ & $28(18.1)$ & 154 \\
\hline Quintile 5 & $136(78.6)$ & $28(16.2)^{\dagger \neq}$ & $9(5.2)$ & $37(21.4)$ & 173 \\
\hline Group & $721(84.1)$ & $64(7.5)$ & $31(3.6)$ & 95 (11.1) & 816 \\
\hline $\begin{array}{l}\text { Ow/Ob }=\text { overweigh } \\
\text { *International BMI } \\
{ }^{p}<0.05 .\end{array}$ & d obesity. & 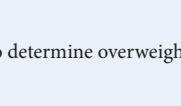 & obesity. & & \\
\hline
\end{tabular}

black learners $(8.8 \%)$. This was the case in the 6- and 7-year-old groups and in the overall group. In a study on 10 - 15-year-old children living in the NWP of SA, Kruger $e t$ al. ${ }^{[23]}$ also found that white children had the highest prevalence of overweight and obesity (white 14.2\%, black 7.1\%, Indian 6.4\% and mixed ancestry $2.9 \%$ ), although this study was conducted on older children. Research by Reddy et al., ${ }^{[24]}$ based on the National Youth Behaviour Survey in 2002, reported similar results, where white boys and girls aged 13 - 19 years showed a higher prevalence of overweight and obesity than black boys and girls. Very few research results are available in SA concerning overweight and obesity among other ethnic groups such as mixed ancestry and Indian populations. A study in the NWP among 10 - 12-year-old girls indicated that $16.5 \%$ of girls were overweight and $4.9 \%$ were obese. ${ }^{[25]}$ These researchers reported differences between racial groups in overweight ( $21.3 \%$ white, $15.81 \%$ black, $9.1 \%$ mixed ancestry, $17.4 \%$ Indian) and obese (8.5\% white, $4.4 \%$ black, $0 \%$ mixed ancestry, $8.7 \%$ Indian) girls. ${ }^{[25]}$ The limited number of mixed ancestry and Indian children in our study is acknowledged as a limitation of the study, making comparisons in this regard difficult. More research is thus recommended to obtain more information on overweight and obesity trends in these ethnic groups in SA.

Learners in quintile 4 and 5 schools, representing schools in areas with higher socioeconomic circumstances, showed significantly higher prevalence rates of overweight in both the 6- and 7-year-old groups compared with those in quintile 1 - 3 schools. Quintile 4 schools also showed significantly higher levels of obesity compared with lower quintile schools. These results agree with the findings of several researchers, ${ }^{[6,724,26]}$ indicating that children living in lower socioeconomic areas in SA have lower prevalence rates of overweight and obesity. Steyn et al. ${ }^{[7]}$ also reported that the highest prevalence of overweight and obesity among younger children ( 1 - 8 years) in SA was seen in urban areas. Kruger et al. ${ }^{[23]}$ reported similar findings among 10 - 15-yearold children, where a higher prevalence of overweight and obesity was found in urban areas and smaller households. Monyeki et $a l .{ }^{[26]}$ reported that very few black children in rural areas of age 7 years were above the NHANES III (Third National Health and Nutrition Examination Survey) 85th percentile for BMI. Therefore, it seems that SA children from higher SES have the highest rates of overweight and obesity, which is different to the findings of studies conducted in other countries such as the USA, which indicated that the highest rates of obesity and severe obesity are among children who are underserved by the healthcare system. ${ }^{[3,4]}$ These studies are, however, conducted in FirstWorld countries, while SA is considered a developing country with high socioeconomic disparities. Furthermore, researchers in India 
linked obesity among children of high SES with provision of generous pocket money, which is mostly spent on energy-dense foods. ${ }^{[27]}$ Researchers also concluded that 3 - 18-year-old children in Greece spent their pocket money on high-energy, fatty and sugary foods that contributed to the development of overweight and obesity, while small amounts of pocket money were linked with healthier body weight. ${ }^{[28]} \mathrm{A}$ tuck shop truths survey conducted among 20 schools and 652 parents in the Gauteng area of SA in June 2013 confirmed that more than a quarter of children are sent to school without food and have to rely on the foods sold to them at tuck shops. ${ }^{[29]}$ Eighty percent of these children are provided with at least R10 per day to spend at tuck shops, where high percentages of unhealthy food are sold to them. The survey also suggested that the health content of lunch boxes that are packed for children can be improved. The high overweight and obesity statistics found in quintile 4 and 5 schools in our study support the findings of this survey.

\section{Conclusion}

More than $10 \%$ of grade 1 learners in the NWP of SA were overweight or obese, indicating that 1 in 10 school beginners is either overweight or obese when they enter the formal school system in grade 1 . The prevalence of overweight was significantly higher in 7-year-olds compared with 6-year-olds, while obesity rates were slightly lower in the older children. These results can help health professionals, policymakers and child development experts to plan future strategies to address problems relating to overweight and obesity. Health education curricula and physical education programmes that include physical activity, diet and behaviour modification, and which foster an enabling environment in which children can make healthy food choices, should also be implemented in schools. More research is, however, needed to obtain a better understanding of contributing factors to childhood obesity in the diverse SA population, while longitudinal research is recommended to determine if the prevalence of overweight and obesity continues to rise with increasing age.

Acknowledgements. This work is based on research supported by the National Research Foundation (NRF) of SA, the National Lottery Distribution Fund and the Focus area of PhASRec, which are acknowledged for their contributions.

The authors would also like to express their gratitude to the postgraduate students, research team, and the schools and learners who participated in the study.

Disclaimer. any opinion, findings and conclusions or recommendations expressed in this material are the opinion of the author(s) and the NRF does not accept any liability in regard thereto.

\section{References}

1. Hills AP, King NA, Armstrong TP. The contribution of physical activity and sedentary behaviours to the growth and development of children and adolescents. Sports Med 2007;37(6):533-545. [http://dx.doi.org/10.2165/00007256-200737060-00006]

2. World Health Organization. Obesity and Overweight. Geneva: World Health Organization, 2011b. http://www.who.int (accessed 4 May 2011).

3. Phipps SA, Burton PS, Osberg LS, et al. Poverty and the extent of child obesity in Canada, Norway and the United States. Obes Rev 2006;7(1):5-12. [http://dx.doi. org/10.1111/j.1467-789X.2006.00217.x]

4. Skelton JA, Cook SR, Auinger P, et al. Prevalence and trends of severe obesity among US children and adolescents. Acad Pediatr 2009;9(5):322-329. [http://dx.doi. org/10.1016/j.acap.2009.04.005]

5. Walker ARP, Adam F, Walker BF. World pandemic of obesity: The situation in Southern African populations. Public Health 2001;115(6):368-372. [http://dx.doi. org/10.1038/sj.ph.1900790]

6. Armstrong MEG, Lambert MI, Sharwood KA, et al. Obesity and overweight in South African primary school children - the health of the nation study. S Afr Med J 2006;96:439-444.

7. Steyn NP, Labadarios D, Maunder E, et al. Secondary anthropometric data analysis of the national food consumption survey in South Africa: The double burden. Nutrition 2005;21(1):4-13. [http://dx.doi.org/10.1016/j.nut.2004.09.003]

8. Shisana O, Labadarios D, Rehle T, et al. South African National Health and Nutrition Examination Survey (SANHANES-1). Cape Town: HSRC Press, 2013.

9. Daniels SR. The consequences of childhood overweight and obesity. Future Child 2006;16(1):47-67.

10. Graft C, Koch B, Kretschmann-Kandel E, et al. Correlation between BMI, leisure habits and motor abilities (CHILT-Project). Int J Obes Relat Metab Disord 2004;28(1):22-26. [http://dx.doi.org/ 10.1038/sj.ijo.0802428]

11. D'Hondt E, Deforche B, De Bourdeaudhuij I, et al. Relationship between motor skill and body mass index in 5- to 10-year-old children. Adapt Phys Activ Q 2009;26(1):21-37.

12. Okely AD, Booth ML, Chey T. Relationship between body composition and fundamental movement skills among children and adolescents. Res Q Exerc Sport 2004;75(3):238-247. [http://dx.doi.org/10.1080/02701367.2004.10609157]

13. Marfell-Jones M, Olds T, Stewart A, et al. International Standards for Anthropometric Assessment. Potchefstroom: International Society for the Advancement of Kinanthropometry, 2006:137.

14. Cole TJ, Belizzi MC, Flegal KM, et al. Establishing a standard definition for child overweight and obesity worldwide: International survey. BMJ 2000;320(7244):12401243. [http://dx.doi.org/10.1136/bmj.320.7244.1240]

15. Statsoft. Statistica for Windows. Release 5.5: General conventions and statistics. Tulsa, USA: Statsoft, 2011.

16. Cohen J. Statistical Power Analysis for the Behavioral Science. New York: Erlbaim, 1988

17. Rossouw HA, Grant CC, Viljoen M. Overweight and obesity in children and adolescents: The South African problem. S Afr J Sci 2012;108(5/6):Art. 907, 7 pages. [http://dx.doi.org/10.4102/sajs.v108i5/6.907]

18. Rolland-Cachera MF, Casetbon $\mathrm{K}$, Arnault, $\mathrm{N}$, et al. Body mass index in 7 9-year-old French children: Frequency of obesity, overweight and thinness. Int J Obes Relat Metab Disord 2002;26(12):1610-1616. [http://dx.doi.org/10.1038/ sj.ijo.0802146]

19. Padez C, Fernandes T, Mauroa I, et al. Prevalence of overweight and obesity in 7 9-year-old Portuguese children: Trends in body mass index from 1970 - 2002. Am J Hum Biol 2004;16(6):670-678. [http://dx.doi.org/10.1002/ajhb.20080]

20. Jinabhai CC, Taylor M, Coutsoudis A, et al. A health and nutritional profile of rural school children in KwaZulu-Natal, South Africa. Ann Trop Paediatr 2001;21(1):50-58. [http://dx.doi.org/10.1080/02724930020028920]

21. Jinabhai CC, Taylor, M, Sullivan KR. Implications of the prevalence of stunting, overweight and obesity amongst South African primary school children: A possible nutritional transition? Eur J Clin Nutr 2003;57(2):358-365. [http://dx.doi.org/10.1038/ sj.ejcn.1601534]

22. Kruger HS, Steyn NP, Swart EC, et al. Overweight among children decreased, but obesity prevalence remained high among women in South Africa, 19992005. Public Health Nutr 2011;15(4):594-599. [http://dx.doi.org/10.1017/ S136898001100262X]

23. Kruger R, Kruger HS, MacIntyre UE. The determinants of overweight and obesity among 10- to 15-year-old schoolchildren in the North West Province, South Africa - the THUSA BANA study. Public Health Nutr 2006;9(3):351-358. [http://dx.doi. org/10.1079/PHN2005849]

24. Reddy SP, Resnicow K, James S, et al. Underweight, overweight and obesity among South African adolescents: Results of the 2002 National youth risk behaviour survey. Public Health Nutr 2008;12(2):203-207. [http://dx.doi.org/10.1017/S1368980008002656]

25. Pienaar AE, Bell GJ, Dreyer LI. The incidence of obesity and developmental coordination disorder (DCD) among 10- - 12-year-old girls of different race groups in the North West Province: Thusa Bana Study. African Journal for Physical Health Education, Recreation and Dance 2007;13(1):221-237

26. Monyeki KD, Van Lenthe FJ, Steyn NP. Obesity: Does it occur in African children in a rural community in South Africa? Int J Epidemiol 1999;28(2):287-292.

27. Raychaudhuri M, Sanyal D. Childhood obesity: Determinants, evaluation, and prevention. Indian J Endocrinol Metab 2012;16(Suppl 2):S192-S194. [http://dx.doi. org/10.4103/2230-8210.104037]

28. Grammatikopoulou MG, Galli-Tsinopoulou A, Daskalou E, et al. Is pocket money an indicant of dietary intake and obesity? Arch Dis Child 2008;93(Suppl 2):pw4.

29. Tuck shop truths study reveals poor nutritional offerings. http://www.bizcommunity. com/Article/196/329/98197.html (accessed 13 June 2013) 